\title{
Shelters can negatively affect growth and welfare in lumpfish if feed is delivered continuously
}

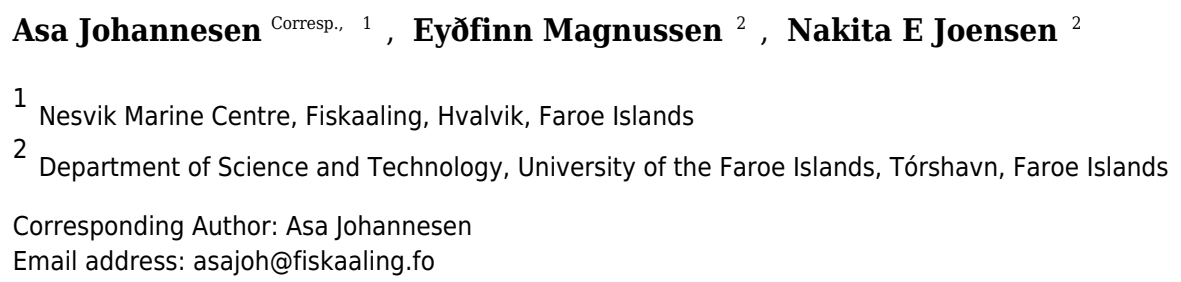

Due to the socioeconomic importance of salmon farming in the North Atlantic and the economic impact of sea lice in this industry, there is high demand for novel pest control methods. One such method is the use of cleaner fish to remove the lice from the salmon. A cleaner fish that has recently gained in popularity due to its ability to work in cold water, is the lumpfish (Cyclopterus lumpus). This fish varies in efficiency, but when mortality is low and cleaning optimal, the fish are successful in keeping parasite burdens low. However, there is some concern for the welfare of lumpfish in the industry, because mortality is often high. This is sometimes attributed to inadequate feeding and shelter. Here we compare growth, body condition, and fin health of fish reared for four weeks in a crossed treatment design crossing shelter availability (shelter vs none) and feed delivery method (manual meal time feeds and continuous automated feeding). In terms of weight gain, shelter availability interacted with feeding method, with fish that had access to shelters and were fed using automated feeders gaining less weight than other fish. Fin health was not affected, but body condition was lowered both by access to shelter and being fed continuously. The results indicate a need to carefully consider how feeding method and shelter use is combined, both in cages and during rearing on land. 
Shelters can negatively affect growth and welfare in lumpfish if feed is delivered continuously.

Asa Johannesen ${ }^{1}$, Nakita E. Joensen ${ }^{2}$, Eyðfinn Magnussen²

${ }^{1}$ Nesvik Marine Centre, Fiskaaling, Hvalvik, Faroe Islands

${ }^{2}$ Department of Science and Technology, University of the Faroe Islands, Tórshavn, Faroe Islands

Corresponding author: Ása Johannesen ${ }^{1}$

Email address: asajoh@fiskaaling.fo 
1

2 Due to the socioeconomic importance of salmon farming in the North Atlantic and the economic

3 impact of sea lice in this industry, there is high demand for novel pest control methods. One such

4 method is the use of cleaner fish to remove the lice from the salmon. A cleaner fish that has

5 recently gained in popularity due to its ability to work in cold water, is the lumpfish (Cyclopterus

6 lumpus). This fish varies in efficiency, but when mortality is low and cleaning optimal, the fish

7 are successful in keeping parasite burdens low. However, there is some concern for the welfare

8 of lumpfish in the industry, because mortality is often high. This is sometimes attributed to

9 inadequate feeding and shelter. Here we compare growth, body condition, and fin health of fish

reared for four weeks in a crossed treatment design crossing shelter availability (shelter vs none)

and feed delivery method (manual meal time feeds and continuous automated feeding). In terms

of weight gain, shelter availability interacted with feeding method, with fish that had access to

shelters and were fed using automated feeders gaining less weight than other fish. Fin health was

not affected, but body condition was lowered both by access to shelter and being fed

continuously. The results indicate a need to carefully consider how feeding method and shelter

use is combined, both in cages and during rearing on land.

\section{Introduction}

Aquaculture is a growing industry and already now outcompetes fisheries as a source of seafood protein $(\mathrm{FAO}, 2016)$. Because of increasing demand, some sectors in the industry are under pressure to produce ever increasing volumes of food. The Atlantic Salmon (Salmo salar) farming industry is one of the sectors, where production has increased rapidly in recent years (FAO, 2016). The increased production is at risk of impacting fish welfare (Turnbull et al., 2005; Jansen et al., 2012). One of the problems in the North Atlantic stems from two parasitic copepods, 
24 Lepeoptheiris salmonis (salmon louse) and Caligus elongatus (sea louse). These parasites are

25 often referred to collectively as 'sea lice' and they have a large impact on the salmon farming

26 industry, causing huge economic losses (Costello, 2009; Abolofia, Asche \& Wilen, 2017).

27 Salmon lice consume mucous, skin, and blood from salmon (Costello, 2006), causing sub-lethal

28 injury to salmon and in extreme cases, mortality (Skilbrei et al., 2013). To avoid this impact on

29 both salmon production and welfare, farming companies and governments alike implement a range of rules and methods to keep infestation levels low. Historically, louse control methods

31 have mostly consisted of chemical treatments and management practices designed to lower exposure to lice. While management practices are mostly sound, lice have proven to grow resistant to chemotherapeutants soon after they become available on the market (Aaen et al., 2015), so industry has been forced to find new ways of preventing accelerating louse infestations.

Many of the new louse prevention or removal methods are physical in nature. They involve either preventing louse access to salmon by using fine mesh "skirts" on cages or making the salmon swim at depths below where most of the free floating lice are (Frank et al., 2014; Stien et al., 2016), or they involve treatments using fresh water, warm water or pressurised water to flush the lice off the salmon (Grøntvedt et al., 2015; Lekang, Salas-Bringas \& Bostock, 2016). All of these treatment and prevention methods are at risk of causing reduced salmon welfare or

42 financial losses to farmers. Skirts can cause poor oxygenation (Stien et al., 2012) and "taking the 43 surface away" from the salmon prevents natural behaviours (Barber, 2007). The various

44 mechanical delousing methods cause stress and injury with resulting low appetite and mortality 45 (reviewed in Bui et al., 2017). Some more inventive methods include a laser removal tool (Beck, 46 2015) and vegetable supplements in the feed (Jodaa Holm et al., 2016; O'Shea et al., 2017), but 
47 these are not yet commercially viable products. Finally, salmon farmers have been using cleaner

48 fish, first a range of wrasse species (Fam. Labridae) starting in the 1980's (Bjordal, 1988; Deady,

49 Varian \& Fives, 1995; Skiftesvik et al., 2014) and more recently, lumpfish (Cyclopterus lumpus)

50 (Imsland et al., 2014a; Eliasen et al., 2018). Despite their generally hardy nature, lumpfish

51 mortality on farms has been high and efficiency variable (Powell et al., 2017).

52 Lumpfish are a sedentary species with little buoyancy control due to the lack of swim bladder

53 (Davenport, 1985). They use a sucker to attach to smooth surfaces and will generally only swim

54 when necessary to avoid danger or to forage for food (Williams \& Brown, 1991). Lumpfish that

55 clean salmon will approach docile salmon, search for lice on the salmon, and pick the lice that

56 they find off the salmon (supplementary video file, S1). This behaviour is quite energy intensive,

57 especially during times with strong currents or waves. In general, approximately $10 \%$ of

58 lumpfish can be expected to have recently consumed lice at any one point in time on the Faroe

59 Islands, though this is highly affected by seasonal availability of plankton causing a shift from 0-

$605 \%$ of lumpfish consuming lice when planktonic prey is available, to $15-20 \%$ when no

61 planktonic prey is available (Eliasen et al., 2018). There is also some question as to the reliability

62 of using lice found in the stomach as an indicator of how many lumpfish consume lumpfish

63 because digestion times vary (Eysturskarð, Johannesen \& Eliasen, 2016). The nutritional needs

64 of lumpfish are not well documented, but given their prey choice, it is unlikely that lice meet

65 those needs. However, it is possible that lumpfish prefer planktonic prey because they can

66 employ a sit-and-wait strategy when planktonic prey is plentiful and simply stay attached to their

67 shelters until the prey floats by in the current. There is no indication that lumpfish body

68 condition is affected by louse burden in a salmon farm (Eliasen et al, in prep), so it is unlikely

69 that lice play a major role in terms of nutrition for lumpfish. 
Lumpfish are generally considered to use shelters, mainly for two purposes. They hide in or under them as an anti-predator behaviour and attach to them to rest (Imsland et al., 2014b, 2015).

This second use is related to their lack of swim bladder and the fact that their near spherical bodies are not well suited for rapid continuous swimming (Davenport, 1985). Because of the dual use of shelters, efforts are made to create shelters in salmon cages that accommodate both needs. The first shelters commonly used were variations on artificial seaweeds similar to those used for wrasses (see Skiftesvik et al., 2013). These shelters provided excellent options for hiding, but were not sturdy enough to provide suitable resting space (verbal feedback from salmon farmers). Other shelters, made from hard plastic, have provided good rigid resting space but have not provided much in terms of hiding places, as they are usually flat vertical surfaces, (see also Imsland et al., 2015).

Feed and shelter for lumpfish can become limited resources on a salmon farm. Feeding practices for lumpfish usually involve automated feeders dispersing feed in a limited area, though some farms use manual feeding. When feed is delivered manually, this is usually done once or twice per day with large quantities of feed delivered alongside the cage net and near the shelters. The fish keeper will look out for the fish and deliver more feed where the fish can be seen approaching the feed. Lumpfish are a docile and easily tamed species, so will usually approach fish keepers when they notice them. Though there is very little literature on how to best feed lumpfish, there is some indication that meal-time or "pulse" feeding promotes growth (Brown, Wiseman \& Kean, 1997) and a more efficient feeding behaviour with less time spent foraging. On the contrary, fish may spend more time foraging and less time resting if feed is delivered continuously within a small area (Killen, Brown \& Gamperl, 2007). Lumpfish will consume free floating feed pellets as well as pellets lying on the bottom of the tank (observation from the 
93 production at Nesvík Marine Centre). If shelters are located in such a way that a trade-off

94 between an ideal resting/hiding place and feed availability emerges, there is a risk of competition

95 for the best locations both in terms of shelter and feed (Pulliam \& Caraco, 1984; Williams \&

96 Brown, 1991). Because of the potential competition related to the two resources, shelters and

97 food, it is possible that shelter availability may negatively affect lumpfish growth or welfare if

98 feed is a limited or difficult resource to gain access to. However, it is not currently clear whether

99 continuous automated feeding provides better feed availability than manual "mealtime" feeding

100 in this situation.

101 The aim of this study is to investigate the effect of shelters and feeding methods on lumpfish

102 welfare, expressed by growth, body condition, and fin health. We use a crossed design with 103 shelter availability: "Shelter" or "No shelter" crossed with two feeding methods: "Manual

104 feeding three times per day" and "Automated feeding every 10 minutes during the day". We

105 expect that a shelter has a positive effect on growth and welfare and that manual feeding

106 provides better growth due to prolonged resting times in between feeds. We also expect that "fin

107 health" will be negatively affected by access to a shelter due to competition for optimal resting

108 spaces, which causes a higher concentration of fish in a small area.

Methods

111 Setup

112 This experiment was carried out at Fiskaaling's 'Nesvík Marine Centre' where lumpfish are 113 experimentally bred for the purposes of establishing a domestic brood stock. Therefore, the fish 114 used in this experiment were bred in captivity with a mixed ancestry of wild and captive bred 
115 brood stock and were accustomed to a captive environment with limited shelter access and a

116 mixture of automated and manual feeding. For the experiment, 200 lumpfish (weight: $3.61 \mathrm{~g} \pm$

117 0.06; Mean $\pm \mathrm{SE}$ ) were taken from production tanks at the Centre and evenly distributed amongst

11820 experimental tanks (10 fish per white fibre glass tank, $125 \mathrm{~L}$, approximately $50 \mathrm{~cm} \times 50 \mathrm{~cm} \times$

$11950 \mathrm{~cm}$ ). Each fish was tagged using visible injectable elastomer (VIE) colour tags (Northwest

120 Marine Technology Inc) injected ventrally near the surface of the skin in two locations (Fig S1).

121 The duration of the experiment was 28 days, from 01-02-2017 to 01-03-2017. At the beginning

122 and end of the experiment, each fish was weighed in grams to two decimal points precision and

123 total body length and height was measured to nearest $\mathrm{mm}$. Additionally, all fish were assessed

124 for fin damage on a scale from 1 to 4; 1: No damage (straight tail fin). 2: Moderate damage

125 (small incisions on tail fin). 3: Severe damage, (large parts of fin missing, but without wounds).

126 4: Injury (missing tail fin and open wounds). Fish were anaesthetised using an aerated metacaine

127 bath $(0.2 \mathrm{~g} / \mathrm{L})$ before handling to minimise stress. All tanks had flow through aerated sea water

$128\left(7^{\circ} \mathrm{C}\right)$, with a flow rate of two litres per minute or a full tank exchange every hour. Half lids

129 provided partial cover while allowing for tank maintenance and overhead lights (121.00 lux \pm

1303.48 at surface) were set to a 12:12 light:dark schedule. Two experimental treatments were

131 crossed to create four treatment groups with five tanks in each group. The treatments were;

132 'feeding method': 1) manual meal time feeding three times per day, 2) automated feeding for

133 five seconds every ten minutes during the 12 light hours, and 'shelter availability': 1) shelter

134 available, 2) no shelter available. Treatments were randomised amongst the tanks using the

135 random number generator in Excel to account for any variation amongst tanks in light conditions

136 and human disturbance during the day. Some fish were also photographed in order to document a 
137 difference in skin pigmentation that was noted upon measuring the fish at the end of the trial.

138 One fish died of unknown causes during the trial period and has been excluded from analysis.

139 Feeding

140 The feed used in this experiment was $1.5 \mathrm{~mm}$ "Lumpfish Grower" feed pellets by Biomar, which

141 is the standard feed used at Nesvík Marine Centre. These feed pellets are slow sinking with a

142 protein content of $56 \%$ and lipid content of $15 \%$. Since the lumpfish were accustomed to this

143 feed, there was no adjustment period or change in their diet as a consequence of this experiment.

144 Lumpfish can be expected to approximately double their weight every four weeks at normal

145 growth. Daily feed amount was adjusted to be at least 5\% of the expected final weight of the fish

146 per day, which ought to be in excess of satiation. An excess of feed was delivered to ensure

147 minimal competition and that insufficient daily feed quantity would not cause lowered growth in

148 any group. Feed was delivered in the light period between 07:00 and 19:00 by automated feeders

149 providing feed for 5 seconds every 10 minutes and manual meal times were at 08:30, 12:30, and

150 15:30. Automated feeders were regularly checked to ensure that they were feeding the necessary

151 amount of feed and manual feed was divided into three meal times ensuring that no less than the

152 minimum $5 \%$ of expected final biomass was provided in total (despite apparent satiation).

153 Uneaten feed was removed once per day (in the morning before the first manual feed) as part of

154 the daily tank cleaning routine. Uneaten pellets on the tank floor were used as an additional

155 means of estimating whether sufficient feed was being delivered by the automated feeders.

156 Shelter

157 All tanks were white, cubical with flat bottoms, had a single green inlet pipe, and a central grey

158 drainage pipe. The pipes offered some opportunity for substrate choice and potential colour

159 matching in the unsheltered tanks, as lumpfish are often observed attaching to features in a tank 
160 contrasting with the background colour (personal observation). However, they were unavoidable

161 in our setup and did not provide any opportunity for hiding. The shelters were constructed from

162 square black PE drainage pipes cut in half lengthwise to create two right angle lengths of shelter

163 (40 cm long, total area was $0.2 \mathrm{~m}^{2}$ ). These were hung horizontally (roof style, see Fig S2) in

164 twos, with one above the other and a gap between them of $20 \mathrm{~cm}$. This construction allowed the

165 fish to sit on top of, in between, and under shelters, allowing a large variation in degree of

166 sheltering, from completely obscured from the top and sides of the tank to completely visible but

167 slightly camouflaged by colour matching. Shelter usage was not recorded in a structured manner,

168 but casual observation indicated that approximately $70 \%$ of the fish chose to sit underneath the

169 shelters in such a way that they were not visible to people looking down into the tank.

\section{Analysis}

171 A mixed effects generalized linear model was constructed using 'weight gain' as the response

172 variable, 'shelter availability' and 'feeding method' as the predictor variables, and 'tank' as a

173 random effect. The analysis was carried out using the package "lme4" (Bates et al., 2015). A

174 linear model was constructed to further investigate differences between the four treatment groups

175 because the initial mixed model produced a significant interaction, making it difficult to interpret

176 individual factor effects. Fish weigh, length and height was used to get an estimate of 'body

177 condition' (weight $(\mathrm{g}) /($ length $(\mathrm{cm}) \mathrm{x}$ height $(\mathrm{cm}))$ ). Body condition at the end of the trial was

178 used for constructing a mixed model with the same predictor variables as for 'weight gain',

179 though a post-hoc test was not necessary as there was no interaction between the predictor

180 variables. To investigate fin damage a different approach was necessary due to the more

181 subjective measure of fin damage scores. Scores were saved as an ordered factor due to their

182 non-linear nature. The package "ordinal" (Christensen, 2015) was used construct a cumulative 
183 link mixed model with the Laplace approximation for fin damage scores. Two models were

184 constructed; one for change in fin damage score from the beginning to the end of the trial, and 185 one for effect of treatment. All models used were mixed effects models with 'tank' as the 186 random effect due to the dependent nature of individuals within the same tank, especially 187 considering that within-tank competition might occur. All analyses were done in R (R Core 188 Team, 2017). For plotting, ggplot2 (Wickham, 2009) and ggthemes (Arnold, 2017) were used.

\section{Ethical note}

190 The work for this manuscript was reviewed by Fiskaaling's "Animal Experimentation Ethics

191 Committee" (approval number 002). The approval was based on the potential welfare benefit for 192 lumpfish in aquaculture and the limited suffering expected to be caused by this study.

\section{Results}

194 In the 28 days that the trial lasted, mean weight increased by $4.87 \mathrm{~g} \pm 0.14$ (Fig. 1). Feeding 195 method and shelter availability interacted $\left(\right.$ Chi-squared ${ }_{1,16}=7.77, \mathrm{P}=0.005$, Fig 1$)$. A post-hoc 196 linear model revealed that the treatment group 'shelter+automated' had significantly lower 197 increase in weight than all other groups (summary table comparison to 'shelter+automated'; 198 'shelter+manual': $\mathrm{t}=4.59, \mathrm{P}<0.001$; 'no shelter+automated': $\mathrm{t}=3.43, \mathrm{P}<0.001$; ' no 199 shelter+manual': $\mathrm{t}=4.02, \mathrm{P}<0.001$; model statistics: $\mathrm{F}_{3,195}=8.52, \mathrm{P}<0.001$; Fig 1).

200 Fin damage score improved significantly over the course of the experiment $(Z=-10.16, D F=5$, $201 \mathrm{P}<0.001$, Fig 2) and the portion of fish with undamaged fins increased from $13 \%$ to $31 \%$ (Fig. 202 2). No effect of treatment was found on the fin scores at the end of the experiment (shelter: $Z=$ 203 1.41, $\mathrm{P}=0.158$; feeding method: $\mathrm{Z}=-0.18, \mathrm{P}=0.854$, Fig 3). 
204 Body condition at the end of the trial was significantly lower in tanks with a shelter compared to 205 those without shelters (median body condition: 0.71 and 0.75 respectively; $\mathrm{X}^{2}{ }_{1,5}=4.20, \mathrm{P}=$

206 0.04) and significantly higher in tanks with manual feeding than in tanks with automated feeding 207 (median body condition: 0.75 and 0.72 respectively; $\mathrm{X}_{1,5}^{2}=5.33, \mathrm{P}=0.02$ ). No interaction was 208 found between the effects of treatments on body condition $\left(\mathrm{X}_{1,6}^{2}=1.80, \mathrm{P}=0.18\right.$, Fig. 4).

\section{Discussion}

211 In this experiment, we find that both the availability of shelter and the way feed is delivered to 212 lumpfish have consequences for growth and body condition. In terms of body condition, the 213 availability of shelter and automated feeding both reduce body condition such that the group that

214 had lowest body condition was the fish that were provided with a shelter and an automated

215 feeder. In absolute growth, there is a slightly different story, because while shelter availability 216 does seem to lower growth, this is outweighed by manual feeding so that the fish with a shelter 217 available did not have a lower increase in body weight overall compared to fish that did not have 218 a shelter. In terms of fin health, there is no difference between the treatments, but all treatments 219 seem to have been better than conditions in the stocking tanks as fin health improved over time 220 from before the experiment to after. Ordinarily, aggression would be expected to be higher at 221 lower stocking densities, and since stocking density was lower in the trial tanks than in the 222 stocking tanks, a slight degradation in fin health was expected due to aggression and competition

223 for shelter space. Improved fin health suggests that aggression was less prevalent in the trial 224 tanks than in the stocking tanks. There may be other explanatory factors not investigated here.

225 The fish were housed in a recirculation system before the trial and it is possible that the bacteria 
226 in that system were inhibiting fin healing, but there were no obvious signs of infection in any of

227 the fish.

228 It is clear from this experiment that care needs to be taken to ensure that a situation of

229 competition does not occur as a result of feeding method or deployment of shelters. Because of

230 the behavioural need for a resting place and shelter (Imsland et al., 2015), it is important that

231 suitable shelter is provided in sufficient amounts. However, because of a potential for

232 competition for ideal spots in the shelter, care needs to be taken to ensure that feed is delivered in

233 such a way that fish are able to compensate for any extra energy used for competition with

234 increased feed intake (however, see Millidine, Armstrong \& Metcalfe, 2006; Finstad et al., 235 2007).

236 Though enough feed was provided to all tanks to satiate all fish in this experiment, the amount

237 delivered each 10 minutes from an automated feeder was so small, that not all fish had access to

238 feed at the same time. Though not verified through quantitative observations, it is likely that the

239 fish resting closest to where the feed was delivered were the fish that were able to feed first on

240 any given day, and that the rest of the fish would feed only when the first fish reached satiation.

241 It is also possible that a different temporal divergence occurred where dominant fish were able to

242 feed at what was perceived as a less risky time causing lower ranked fish to limit their time spent

243 foraging (Alanärä, Burns \& Metcalfe, 2001). If fish closest to the feed delivery point could eat to

244 satiation first, it is likely that there was competition for the spot in the shelter that was closest to

245 where the feed was delivered. The competition for this spot may have caused increased use of

246 energy and therefore lower growth than in the tanks with no shelter, where the bare tank surface

247 area was large enough for all ten fish to sit near the feed delivery point (compare for example

248 Andrew et al., 2004). 
249 There is evidence in the literature that aggression increases when stocking density is low

250 (Brown, Brown \& Srivastava, 1992; Jørgensen, Christiansen \& Jobling, 1993). Stocking density

251 in this trial was very low, approximately $400 \mathrm{~g}$ per cubic metre compared to common stocking

252 densities of 10-15 kg per cubic metre or more (Hosteland, 2017). It is possible that these results

253 would not be replicated in a system with high stocking density due to decreased opportunity to

254 establish social rank with resulting privileged access to feed. Therefore, the effects found here

255 may be much diminished in a lumpfish production environment. However, in a typical salmon

256 farm, the density of lumpfish is even lower than in this trial, approximately $10 \mathrm{~g}$ per cubic metre.

257 This is a natural consequence of their small size and low numbers in salmon cages of 25-30

258 thousand cubic metres. Therefore, it is possible that situations will arise where lumpfish are able

259 to establish a territory in specific locations in a salmon cage. Considering the need to adequately

260 feed lumpfish in salmon cages, ensuring that all the fish have access to enough feed should be

261 prioritised. As it can be difficult to track lumpfish in a salmon cage, one solution may be to

262 disperse the lumpfish feed using an automated feeder similar to the commonly used salmon

263 feeders and provide an additional daily meal of manually delivered feed near the shelters.

264 Placing the shelters so that the feed can be delivered near them easily is worthy of consideration.

265 However, there are other important considerations in terms of shelter placement that take priority

266 over ease of feed delivery; these considerations being wave and sea current direction as well as

267 shelter cleaning or maintenance.

268 In conclusion, while shelters can offer the necessary enrichment to meet the behavioural needs of

269 lumpfish, careful planning is necessary when feeding methods are decided on. Growth is not

270 necessarily a desirable lumpfish trait in a salmon cage, but body condition certainly is important

271 for their welfare and survival. Similarly, for lumpfish producers, being able to provide optimal 
272 conditions for high growth allows producers to deliver lumpfish to salmon farms at a higher rate.

273 Therefore, based on the results from this experiment, we cautiously recommend that feed is

274 delivered in meal times in such quantities that all fish are able to feed simultaneously, especially

275 in lumpfish rearing facilities. In salmon farms, manual feeding is best combined with automated

276 pulse feeding using a feeder that disperses feed well. This ensures that feed is delivered when

277 manual feeding is impractical, such as in bad weather or when days are much longer than

278 working hours for staff.

\section{References}

281 Aaen SM., Helgesen KO., Bakke MJ., Kaur K., Horsberg TE. 2015. Drug resistance in sea lice: A threat to salmonid aquaculture. Trends in Parasitology 31:72-81. DOI:

Abolofia J., Asche F., Wilen JE. 2017. The Cost of Lice: Quantifying the Impacts of Parasitic Sea Lice on Farmed Salmon. Marine Resource Economics 32:329-349. DOI:

Alanärä A., Burns MD., Metcalfe NB. 2001. Intraspecific resource partitioning in brown trout:

Andrew J., Holm J., Kadri S., Huntingford F. 2004. The effect of competition on the feeding efficiency and feed handling behaviour in gilthead sea bream (Sparus aurata L.) held in tanks. Aquaculture 232:317-331. DOI: 10.1016/S0044-8486(03)00528-3. 
294 Barber I. 2007. Parasites, behaviour and welfare in fish. Applied Animal Behaviour Science

295 104:251-264. DOI: 10.1016/j.applanim.2006.09.005.

296

297

298

299

300

301

302

303

304

305

306

307

308

309

310

311

312

313

314

Bates D., Mächler M., Bolker B., Walker S. 2015. Fitting Linear Mixed-Effects Models Using lme4. Journal of Statistical Software 67:1-48. DOI: 10.18637/jss.v067.i01.

Beck E. 2015. Method and device for destroying parasites on fish. Stingray Marine Solutions. US Patent: US9072281B2

Bjordal Å. 1988. Cleaning symbiosis between wrasse (Labridae) and lice infested salmon (Salmo salar) in mariculture. International Council for the Exploration of the Sea, Mariculture Committee 188:1-8.

Brown GE., Brown JA., Srivastava RK. 1992. The effect of stocking density on the behaviour of Arctic charr (Salvelinus alpinus L.). Journal of Fish Biology 41:955-963. DOI: 10.1111/j.1095-8649.1992.tb02722.x.

Brown JA., Wiseman D., Kean P. 1997. The use of behavioural observations in the larviculture of cold-water marine fish. Aquaculture 155:297-306. DOI: 10.1016/S0044-8486(97)001300.

Bui S., Oppedal F., Sievers M., Dempster T. 2017. Behaviour in the toolbox to outsmart parasites and improve fish welfare in aquaculture. Reviews in Aquaculture. DOI: $10.1111 /$ raq. 12232 .

Christensen RHB. 2015. ordinal - Regression Models for Ordinal Data.

Costello MJ. 2006. Ecology of sea lice parasitic on farmed and wild fish. Trends in parasitology 22:475-83. DOI: 10.1016/j.pt.2006.08.006. 
315 Costello MJ. 2009. The global economic cost of sea lice to the salmonid farming industry.

316 Journal of Fish Diseases 32:115-8. DOI: 10.1111/j.1365-2761.2008.01011.x.

317 Davenport J. 1985. Synopsis of Biological Data on the Lumpsucker, Cyclopterus Lumpus

318 (Linnaeus, 1758). FAO Fish Synopsis 147:31.

319 Deady S., Varian SJA., Fives JM. 1995. The use of cleaner-fish to control sea lice on two Irish 320 salmon (Salmo salar) farms with particular reference to wrasse behaviour in salmon cages. 321 Aquaculture 131:73-90. DOI: 10.1016/0044-8486(94)00331-H.

322 Eliasen K., Danielsen E., Johannesen Á., Joensen LL., Patursson EJ. 2018. The cleaning efficacy 323 of lumpfish ( Cyclopterus lumpus L.) in Faroese salmon ( Salmo salar L.) farming pens in 324 relation to lumpfish size and seasonality. Aquaculture 488:61-65. DOI: 10.1016/j.aquaculture.2018.01.026.

Eysturskarð J., Johannesen Á., Eliasen K. 2016. Application of real-time PCR for specific detection of Lepeophtheirus salmonis in fluid samples from lumpfish (Cyclopterus lumpus) stomachs. Aquaculture International. DOI: 10.1007/s10499-016-0093-y.

Finstad AG., Einum S., Forseth T., Ugedal O. 2007. Shelter availability affects behaviour, sizedependent and mean growth of juvenile Atlantic salmon. Freshwater Biology 52:1710Aquaculture 2016:160. DOI: 92-5-105177-1.

Frank K., Gansel LC., Lien AM., Birkevold J. 2014. Effects of a Shielding Skirt for Prevention 335 of Sea Lice on the Flow Past Stocked Salmon Fish Cages. Journal of Offshore Mechanics 
and Arctic Engineering 137:11201. DOI: 10.1115/1.4028260.

337 Grøntvedt RN., Nerbøvik I-KG., Viljugrein H., Lillehaug A., Nilsen H., Gjevre A. 2015.

338 Thermal de-licing of salmonid fish - documentation of fish welfare and effect. Norwegian

$339 \quad$ Veterinary Institute's Report Series 13.

340 Hosteland LTS. 2017.Best fiskevelferd ved høj tetthet i rognkjeks karene. Available at

341 https://www.kyst.no/article/best-fiskevelferd-ved-hoey-tetthet-i-rognkjeks-karene/(accessed

$342 \quad$ April 5, 2018).

343 Imsland AK., Reynolds P., Eliassen G., Hangstad TA., Foss A., Vikingstad E., Elvegård TA.

344 2014a. The use of lumpfish (Cyclopterus lumpus L.) to control sea lice (Lepeophtheirus

345 salmonis Krøyer) infestations in intensively farmed Atlantic salmon (Salmo salar L.).

346 Aquaculture 424-425:18-23. DOI: 10.1016/j.aquaculture.2013.12.033.

347 Imsland AK., Reynolds P., Eliassen G., Hangstad TA., Nytrø AV., Foss A., Vikingstad E.,

348 Elvegård TA. 2014b. Notes on the behaviour of lumpfish in sea pens with and without

349 Atlantic salmon present. Journal of Ethology 32:117-122. DOI: 10.1007/s10164-014-0397-

$350 \quad 1$.

351 Imsland AK., Reynolds P., Eliassen G., Hangstad TA., Nytrø AV., Foss A., Vikingstad E.,

352 Elvegård TA. 2015. Assessment of suitable substrates for lumpfish in sea pens. Aquaculture 353 International 23:639-645. DOI: 10.1007/s10499-014-9840-0.

354 Jansen PA., Kristoffersen a. B., Viljugrein H., Jimenez D., Aldrin M., Stien A. 2012. Sea lice as 355 a density-dependent constraint to salmonid farming. Proceedings of the Royal Society B:

356 Biological Sciences. DOI: 10.1098/rspb.2012.0084. 
357 Jodaa Holm H., Wadsworth S., Bjelland A-K., Krasnov A., Evensen Ø., Skugor S. 2016. Dietary

358 phytochemicals modulate skin gene expression profiles and result in reduced lice counts

359 after experimental infection in Atlantic salmon. Parasites \& Vectors 9:271. DOI:

$360 \quad 10.1186 / \mathrm{s} 13071-016-1537-y$.

361 Jørgensen EH., Christiansen JS., Jobling M. 1993. Effects of stocking density on food intake,

362 growth performance and oxygen consumption in Arctic charr (Salvelinus alpinus).

363 Aquaculture 110:191-204. DOI: 10.1016/0044-8486(93)90272-Z.

364 Killen SS., Brown JA., Gamperl AK. 2007. The effect of prey density on foraging mode

365 selection in juvenile lumpfish: balancing food intake with the metabolic cost of foraging.

366 Journal of Animal Ecology 76:814-825. DOI: 10.1111/j.1365-2656.2007.01237.x.

367 Lekang OI., Salas-Bringas C., Bostock JC. 2016. Challenges and emerging technical solutions in 368 on-growing salmon farming. Aquaculture International 24:757-766. DOI: 10.1007/s10499$369 \quad$ 016-9994-z.

370

371

372

373

374

375

376

377

Millidine KJ., Armstrong JD., Metcalfe NB. 2006. Presence of shelter reduces maintenance metabolism of juvenile salmon. Functional Ecology 20:839-845. DOI: 10.1111/j.13652435.2006.01166.x.

Dumiak M. 2017.Lice-Hunting Underwater Drone Protects Salmon With Lasers. Available at https://spectrum.ieee.org/semiconductors/optoelectronics/licehunting-underwater-droneprotects-salmon-with-lasers (accessed April 9, 2018).

Powell A., Treasurer JW., Pooley CL., Keay AJ., Lloyd R., Imsland AK., Garcia de Leaniz C. 2017. Use of lumpfish for sea-lice control in salmon farming: Challenges and opportunities. 
Reviews in Aquaculture:1-20. DOI: 10.1111/raq.12194.

379

Pulliam HR., Caraco T. 1984. Living in groups: is there an optimal group size? In: Krebs JR, Davies NB eds. Behavioural ecology: an evolutionary approach. 122-147.

R Core Team. 2017. R: A Language and Environment for Statistical Computing. Vienna, Austria: R Foundation for Statistical Computing.

Skiftesvik AB., Bjelland RM., Durif CMF., Johansen IS., Browman HI. 2013. Delousing of Atlantic salmon (Salmo salar) by cultured vs. wild ballan wrasse (Labrus bergylta). Aquaculture 402-403:113-118. DOI: 10.1016/j.aquaculture.2013.03.032.

Skiftesvik AB., Blom G., Agnalt A-L., Durif CMF., Browman HI., Bjelland RM., Harkestad LS., Farestveit E., Paulsen OI., Fauske M., Havelin T., Johnsen K., Mortensen S. 2014. Wrasse (Labridae) as cleaner fish in salmonid aquaculture - The Hardangerfjord as a case study. Marine Biology Research 10:289-300. DOI: 10.1080/17451000.2013.810760.

Skilbrei OT., Finstad B., Urdal K., Bakke G., Kroglund F., Strand R. 2013. Impact of early salmon louse, Lepeophtheirus salmonis, infestation and differences in survival and marine growth of sea-ranched Atlantic salmon, Salmo salar L., smolts 1997-2009. Journal of fish diseases 36:249-60. DOI: 10.1111/jfd.12052.

Stien LH., Dempster T., Bui S., Glaropoulos A., Fosseidengen JE., Wright DW., Oppedal F. 2016. "Snorkel" sea lice barrier technology reduces sea lice loads on harvest-sized Atlantic salmon with minimal welfare impacts. Aquaculture 458:29-37. DOI: 10.1016/j. aquaculture.2016.02.014.

Stien LH., Nilsson J., Hevrøy EM., Oppedal F., Kristiansen TS., Lien AM., Folkedal O. 2012. 

levels. Aquacultural Engineering 51:21-25. DOI: 10.1016/j.aquaeng.2012.06.002.

401

402

403

404

405

406

407

408
Turnbull J., Bell A., Adams CE., Bron J., Huntingford FA. 2005. Stocking density and welfare of cage farmed Atlantic salmon: Application of a multivariate analysis. Aquaculture 243:121132. DOI: 10.1016/j.aquaculture.2004.09.022.

Wickham H. 2009. ggplot2: Elegant Graphics for Data Analysis.

Williams P., Brown JA. 1991. Developmental changes in foraging-predator avoidance trade-offs in larval lumpfish Cyclopterus lumpus. Marine Ecology Progress Series 76:53-60. DOI: 10.3354/meps076053. 


\section{Figure 1 (on next page)}

Change in weight in the 28 day trial period split into four treatment groups.

Boxes and whiskers describe quartiles for each group of 49 or 50 fish and dots are outliers. 


\section{Figure 2 (on next page)}

Condition of lumpfish fins before and after the trial.

Bars represent the percentage of fish with each fin condition score. Scores represent: 1: No damage (straight tail fin). 2: Moderate damage (small incisions on tail fin). 3: Severe damage, (large parts of fin missing, but without wounds). 4: Injury (missing tail fin and open wounds). 


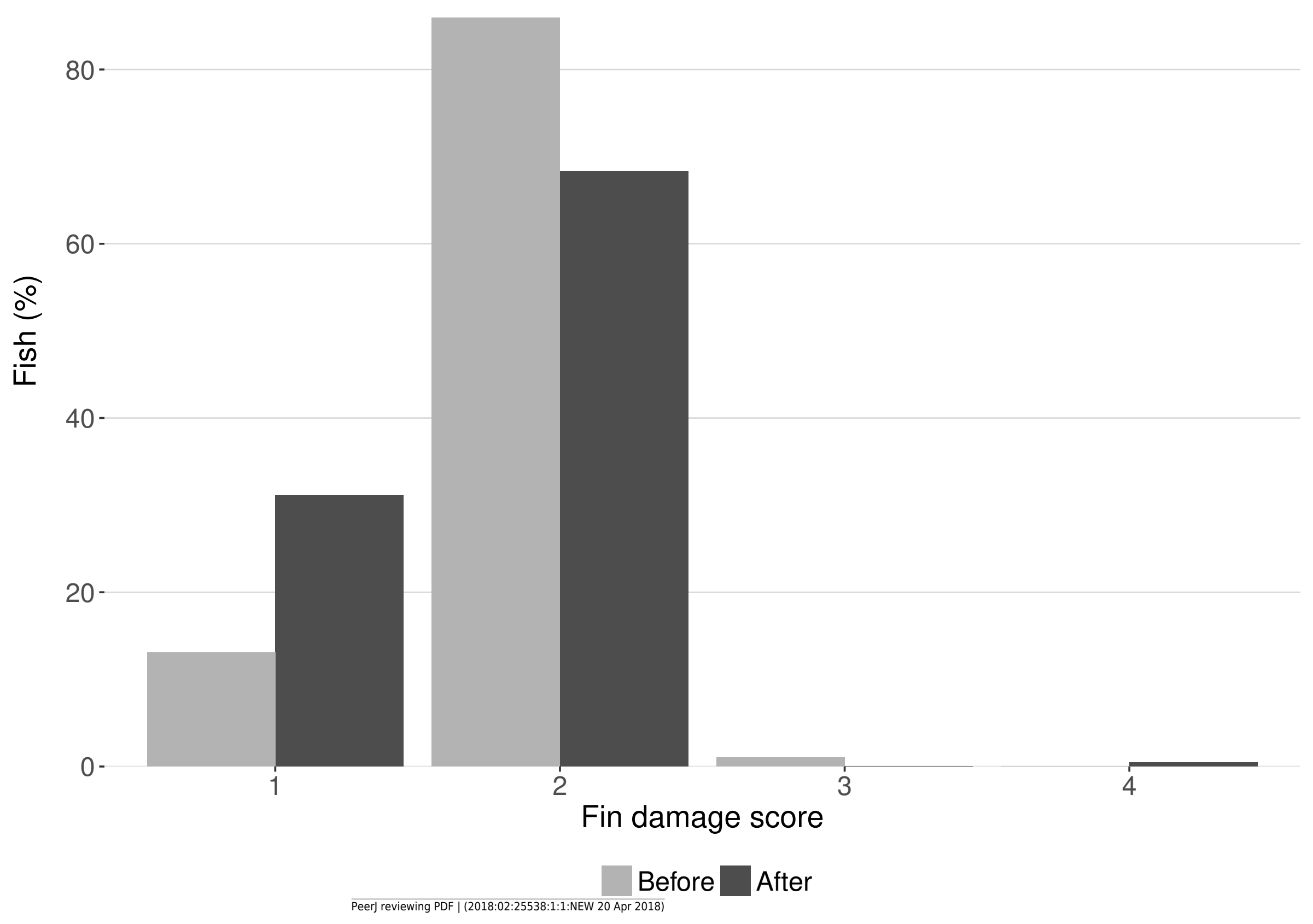


Figure 3 (on next page)

Fin condition scores after the experiment

Bars represent the percentage of fish for each fin condition score split across treatments.

Scores represent: 1: No damage (straight tail fin). 2: Moderate damage (small incisions on tail fin). 3: Severe damage, (large parts of fin missing, but without wounds). 4: Injury (missing tail fin and open wounds). 


\section{Automated, no shelter Automated, shelter Manual, no shelter Manual, shelter}

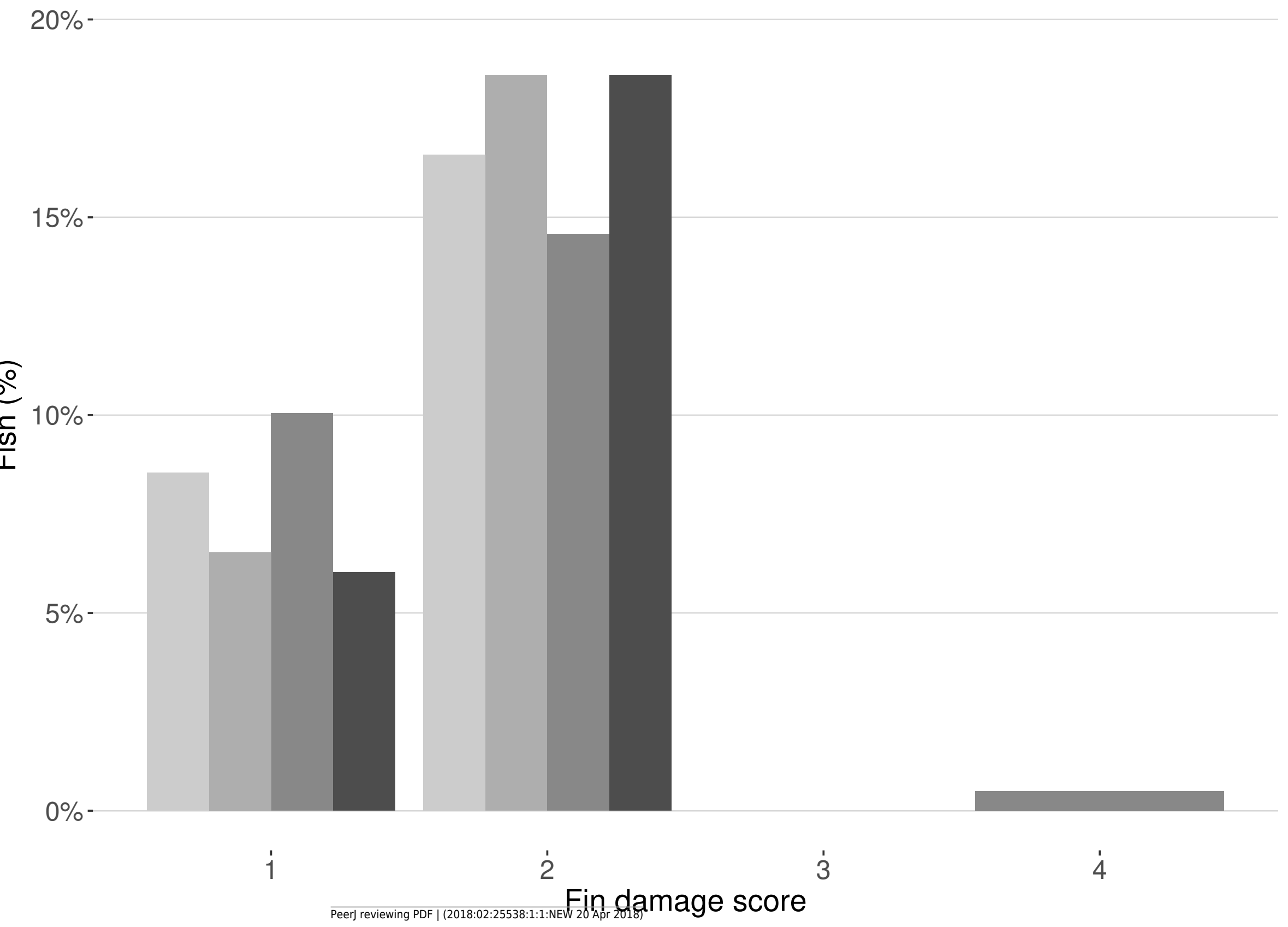




\section{Figure 4 (on next page)}

Body condition of lumpfish at the end of the trial

Boxes and whiskers represent quartiles for each treatment group and dots are outliers. Body condition was calculated from weight, length, and height of each fish: weight(g) / (length $(\mathrm{cm}) *$ height $(\mathrm{cm}))$. 
$0.95-$
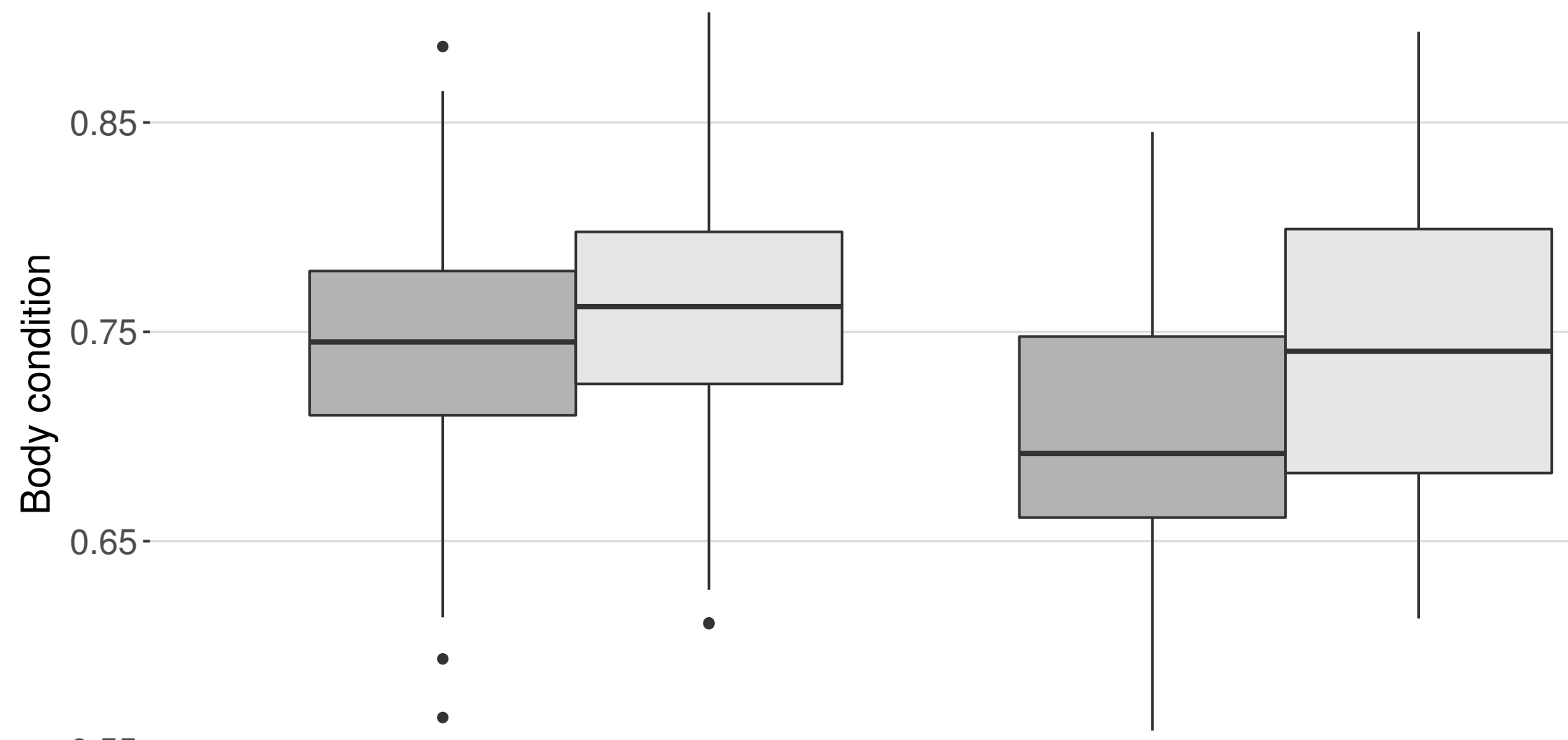

0.55

-

$0.45-$ 